\title{
REFLECTION IN AGILE LEARNING-TEACHING PROCESSES
}

\author{
David INKERMANN, Hendrik LEMBECK, Alexander BRANDIES and Thomas VIETOR \\ Technische Universität Braunschweig, Institute for Engineering Design
}

\begin{abstract}
Modern technology, economy, organisations and social systems are characterised by volatility, uncertainty, complexity and ambiguity. Therefore, distinctive competencies in reflecting own thoughts and actions are required, to be able to adapt these to changing requirements and situations. Reflection is an inherent part of agile methods and processes known from software engineering. In order to teach expand reflection competencies in education of engineering designers, adaption of agile methods to and their implementation in the learning-teaching process is of great interest. In this contribution, we describe an agile, project-based learning-teaching process integrating presence blocks for lectures, feedback and reflection, and virtual learning rooms to support self-learning. Core elements of the concept are different formats and dimensions of reflections, integrated into the learning-teaching process. Regarding reflection formats, we highlight the usefulness of core questions for structured (self-)reflection in teams as well as teachers' deriving of insights for adaption and expansion of learning contents.
\end{abstract}

Keywords: Reflection, project-based learning, agile learning-teaching, agile methods

\section{INTRODUCTION}

Technology, economy, organisations and social systems are changing dramatically due to globalisation and digitalisation, as well as merging of technical, economic and social systems. Resulting changes cannot be foreseen completely, but they define conditions of the working environment of future engineers and product developers. A major challenge for future education and in particular the development of teaching content and training concepts is, to address the described changes of our industrial society and its impacts on the working environment. To deal with these challenges, teaching will focus on enhancing abilities of engineers and product developers from being able to solve problems to being able to define problems [1]. What-to-do capabilities, such as agendasetting or integration, rather than exclusive how-to-do-it activities, like product or service development, have to be taught in education. This change in education ensures that future product developers are able to instruct and guide interdisciplinary teams and thus take responsibility for the transformation of society [2]. The main challenge is highlighted by the following citation: ,, We have to educate students for jobs that don't exist, using technologies that have not been invented in order to solve problems we don't even know are problems yet (YouTube: Did You Know 6.0 Shift Happens)“. Thus, the teaching of comprehensive skills and ways of system thinking, and interdisciplinary cooperation is getting very important. It is hardly possible to impart these skills using established teaching formats for large learning groups. Media-based teaching concepts are therefore of increasing importance, in order to support individualisation of learning processes and acquisition of actionoriented skills.

In this contribution we introduce the concept of agile learning-teaching processes and highlight the importance of applied (self-)reflection to support and guide individual and activity-oriented learning processes.

\subsection{Agile Learning and Teaching Methodology}

The challenges described call for distinctive abilities to reflect on own thoughts and activities from both students and teachers. Reflections are inherent to agile methods, which originate from agile software development and are currently applied to various problems and processes in industry. Such 
methods, like SCRUM [3], are based on a flexible and proactive approach that relies on rapid feedbacks, concentrates on customer needs, and focuses on teamwork and interaction within the (design) process (Agile Manifest). A step-by-step approach helps to identify problems at early stages and to develop suitable solutions quickly [5]. The basic concept of agile teaching and learning methodology is illustrated by Chun [6] who describes two coupled activity loops, cf. Fig. 1. First experiences with applying agile methods in teaching are known from software-related disciplines and project-based courses. Thereby, positive effects on learning outcomes in heterogeneous learning groups as well as the facilitation of interactions between students and teachers are emphasised. At the same time, attention is drawn to the importance of support by digital media and learning platforms as well as the needed of students' distinctive self-management competencies.

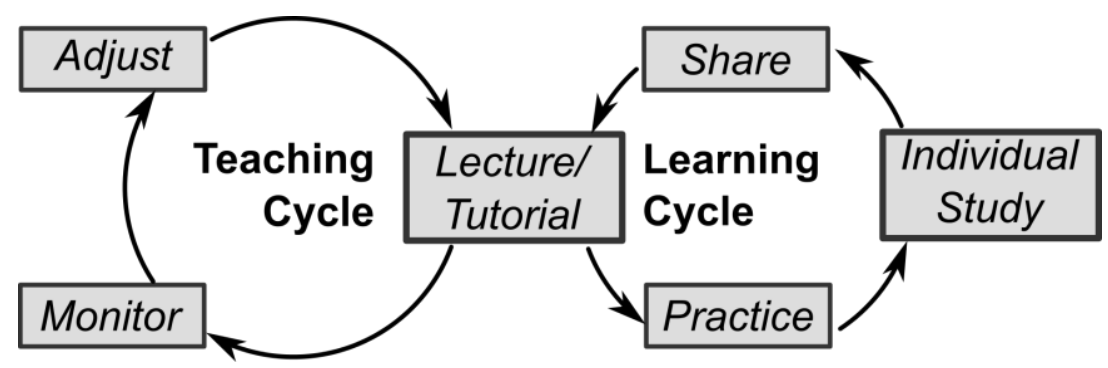

Figure 1. Activity Loops of Students and Teachers in Agile Learning-Teaching Processes, according to Chun [6]

Adapting this basic concept of agile methods to teaching-learning processes in engineering design results in a strong interaction between students and teachers. The agile software development process is replaced by the learning-teaching process with students and teachers as actors. The periods in terms of short cycles - called sprints - during which new functionalities are realised in software development, correspond to a continuous enhancement of students' skills. These increments are called learning increments in the following and are characterised by clear goals and regular feedback loops. Students are supposed to go successfully through to tackle the learning process in small predefined learning units, while the teacher defines goals and provides supportive media. Based on (self-) reflection of the students, the teachers initiate repetitions for deepening existing or provides new content and problems. Thus, reflections are essential elements to interlink the teaching and learning cycles. The following section introduces the basic understanding and forms of (self-)reflection.

\subsection{Importance and Concept of Reflections}

Lauche et al. [7] considered reflections as integral parts of design activities in practice and at the same time as an enhancement of students' motivation for and ownership of their own learning [8]. Therefore, reflection - understood as the ability to recognise what is appropriate and to adapt accordingly - becomes a crucial success factor both for future practitioners in engineering design as well as for effective learning and teaching. There are two perspectives on reflection described in literature. On the one hand "as a description of how practitioners deal with a given situation, and a conscious analysis of one's own thoughts and actions" [7]. Schön [7] calls this reflection-in-action, characterising it based on the idea of design as a reflective conversation with materials in the moment of designing. Thereby, he understands reflection as a thinking that serves to reshape what is done while it is done [9]. On the other hand, refers reflection-on-action to the conscious analysis of one's strategies and actions that were carried out in the past. Based on this understanding reflection has to be understood as meta-cognitive process and skill needed in engineering design [7]. This way, the iterative process of analysis, synthesis and evaluation in engineering design is flanked by a process in which we question whether the procedures, methods and approaches were appropriate.

The mechanism of reflection is often triggered by a mismatch between what is expected and the actual result. Self-reflection begins with recapitulating actions and tasks performed in the past and evaluating the success, with regard to the given object, achieved doing these tasks. Based on this, the necessity to change one's behaviour is analysed in order to motivate changes for future behaviour and strategies. These activities are part of the retrospective. Within the prospective, analyses and modifications of new strategies are performed, cf. Fig. 2. However, it is indicated by empirical studies 
that self-reflection is often avoided in cases of being unsuccessful. Thus, it is important to establish reflection skills as core competencies of engineering designers.

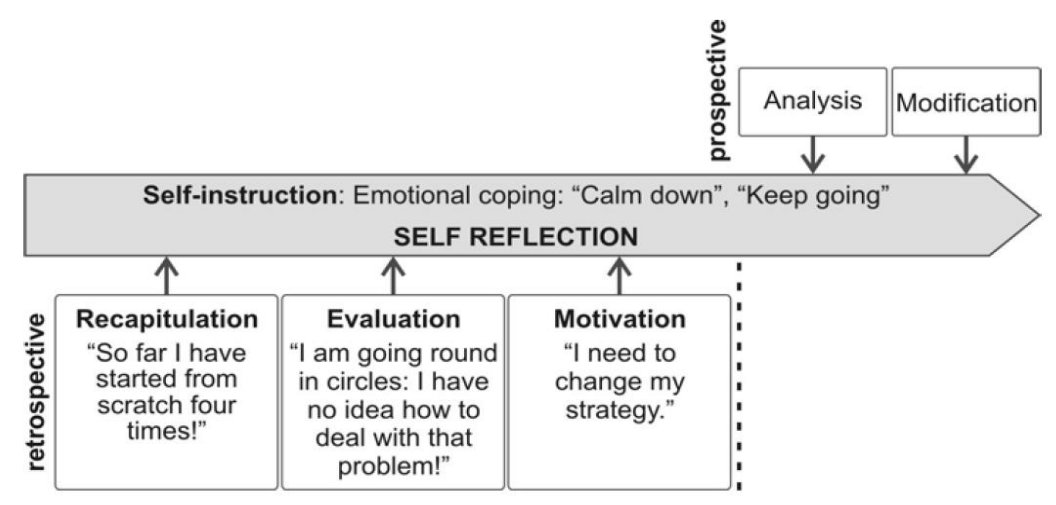

Figure 2. Retrospective and Prospective forms of Self-Reflection, according to Lauche et al. [7]

\subsection{Objective and Focus of the Contribution}

In this contribution we aim at introducing a media-based concept for an agile learning-teaching process as well as different formats and dimensions of (self-)reflection, to support planning and adaption of individual learning processes in engineering design. The concept is intended to support education in large learning groups of pre-graduate students within bachelor studies. Main questions addressed by our contribution are:

- How can media-based self-learning phases be combined with and guided by (self-)reflection?

- Which kinds of reflection formats are suitable and which dimensions of reflection do they imply with regard to required competencies for future product developers?

In order to address these questions, the contribution is structured into the following sections: section 2 introduces the developed concept of a media-assisted agile learning-teaching process and explains its initial implementation in two bachelor courses. Section 3 explains the different formats of (self-) reflection used within the agile learning-teaching process as well as the dimensions they address. In section 4 the proposed concept is discussed, and future work described.

\section{CONCEPT OF MEDIA-ASSISTED AGILE LEARNING-TEACHING}

Based on the concept of agile learning-teaching processes described in section 1.2, as part of an innovation project at the Institute for Engineering Design at TU Braunschweig, a media-assisted agile learning-teaching concept has been developed. The overall objective of the concept was to combine self-learning phases, continuous reflection and guidance of learning processes based on project-based teaching. Therefore, agile methods were adapted for learning and teaching in the field of product development, cf. Fig 3.

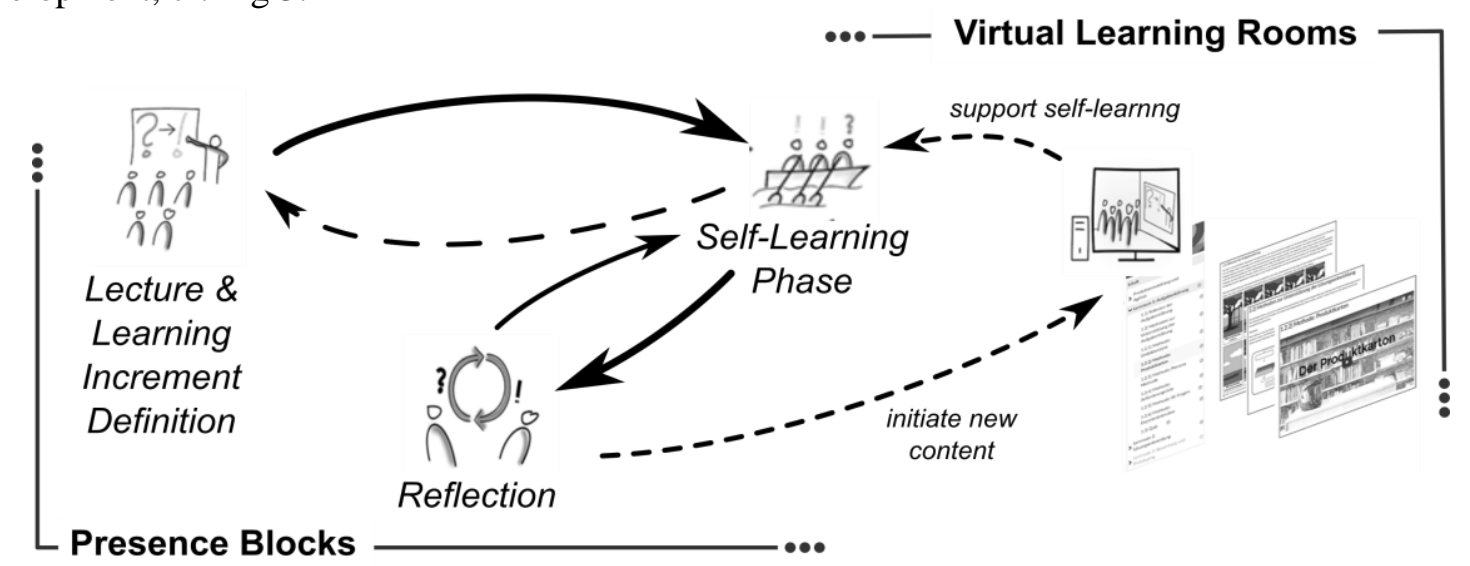

Figure 3. Concept and Elements of the Media-assisted Agile Learning-Teaching Process

The learning-teaching cycle adapted from the SCRUM methodology contains a lecture phase in which the teacher introduces a design task both as objective for an overall development process (design project) and as a learning increment. Thereby, the focus lies on the introduction of basic questions as 
well as the framing of the task to be performed by the students. Within the self-learning phase, the students are requested to work on the given task. To support the fulfilment of the task, different methods and tools are presented and explained within a virtual learning room. Teams of students are asked to select suitable methods and tools in order to successfully do the given tasks. The achieved results are presented and discussed within a presence block. As a reaction to this reflection, on the one hand more detailed tasks are given to the students, in order to deepen the learning content. On the other hand, if required, explanations of the methods and tools within the virtual learning rooms are adapted. This learning-teaching cycle is repeated for different tasks within the development process, like analysis and task clarification, concept generation, as well as evaluation and embodiment. The different learning phases are performed within one to two weeks. The following sections describe the different elements of the media-assisted agile learning-teaching concept.

\subsection{Presence Blocks - Lecture, Feedback, and Reflection}

Core element of the concept are the presence blocks, during which students and teachers meet during the semester. These blocks are used to initially introduce the concept of agile learning-teaching as well as to introduce the engineering project and its different learning phases to the students. Therefore, a short introduction into the design scenario as well as the major kinds of results to be achieved by the students are presented by the teacher. Important is, that the focus here lies on explaining the problem and resulting tasks without commenting on how to solve these. After a self-learning phase, see following subsection, the next presence block is used for structured (self-)reflection on the tasks performed by the students before launching them into the next self-learning phase. During the presence blocks between the self-learning phases, the teachers are supposed to give feedback on the results of the students and also the students are supposed to give feedback on by teachers provided explanations and representation of content used during the self-learning phase. This feedback enables the teachers to adapt, refine and expand the content provided within the virtual learning rooms with regards to the requirements of the students.

\subsection{Virtual Learning Rooms}

The self-learning phases of the students within the agile learning-teaching cycle are supported by virtual learning rooms. These rooms are realised based on a learning platform (StudIP-courseware at TU Braunschweig), which can be used to provide learning content like methods and tools as well as further explanations to the students. Therefore, different media, like structured descriptions, explanatory videos or animations are used to explain methods [10]. Thus, according to [11] these media are used to support the acquisition of knowledge without emphasising "ready-made" media as information content. With the different media on the one hand different learning strategies and types of students are supported. On the other hand, the mixture of media helps to motivate self-learning [12]. Within each learning room there is an excessive supply of methods and tools and the students are asked to select suitable methods for the given task by themselves, based on the understanding they gained. Besides the learning content, each learning room contains a quiz for a first self-assessment of the students.

\subsection{Initial Implementations of the Concept}

The described concept of agile learning-teaching was implemented in two bachelor courses in engineering design at TU Braunschweig. These courses introduce fundamental procedures, methods and tools of engineering design, and contain design projects that have to be performed by teams (4-5 students) within a semester. Within the projects in one course the students had to develop a concept and a prototype for a wheelchair made out of bamboo. Within the projects in the other course, the students had to develop a concept for an electrical adjustable steering column. The courses and projects differed regarding the number of participants (12 and 70 attendees) and the focused parts of a development process: product analysis in case of the steering column and prototyping in case of the wheelchair. In both courses different formats of reflection have been tested.

\section{FORMATS AND DIMENSIONS OF REFLECTION IN AGILE LEARNING- TEACHING PROCESSES}

Like described in section 1.2, (self-)reflection is an inherent part of agile learning-teaching processes. Within the proposed concept the reflection is part of the presence blocks. In order to derive 
conclusions on the learning progress of the students, the comprehensibility of the learning contents (virtual learning rooms), as well as the planned and performed design processes, different reflection formats were implemented. Besides the format, time and frequency of the reflections differ, like presented in Table 1.

Based on the different reflection formats, insights regarding the following aspects are derived:

- Student's understanding of engineering design methods, their selection and their (correct) application to the given design task

- Student's competencies regarding planning and evaluating the design processes and its single phases

- Student's competencies regarding team work and other social skills needed, when performing a design projects within a team

- Teacher's ability to plan and react on learning processes and requirements for support during project work

These insights show, that the conclusions drawn from the reflections address not only technical aspects of the design project and thus elements that are part of a conventional education but also competencies needed to plan and adapt development processes in teams. As a suitable format for (self-)reflection, central questions to be presented to the students were identified, when initially implementing the concept. These questions are for instance:

- What did you do in the past learning increment, what are the results?

- Which methods did you apply and why did you choose them?

- What are you going to do next and how do you plan to work on the tasks in the team?

- What were critical tasks and situations, what kind of support from the teachers is needed?

The questions were answered within the teams presented to the other teams and the teachers, doing short presentation of 20 minutes, using only a flip chart. This helped both the individual students as well as the team to reflect on their process and implicitly discuss their gained understanding of the system, the applied methods and the development process. At the same time the documentation and presentation helps the teachers to gain insights into the learning outcome and give further information and contents for the next learning increment.

Table 1. Formats, Time, Frequency and Stakeholders of (Self-)Reflections within the Agile Learning-Teaching Process

\begin{tabular}{|c|c|c|c|c|}
\hline Name & Format & Time and Frequency & Stakeholders & Conclusions (Dimensions) \\
\hline $\begin{array}{l}\text { Quizzes in } \\
\text { Virtual } \\
\text { Learning } \\
\text { Rooms }\end{array}$ & $\begin{array}{l}\text { Self-Reflection with } \\
\text { structured questions, } \\
\text { no feedback }\end{array}$ & $\begin{array}{l}\text { At the end of each } \\
\text { learning room, within the } \\
\text { virtual learning room }\end{array}$ & Students & $\begin{array}{l}\text { Self-assessment of learning } \\
\text { progress (understanding of } \\
\text { methods) }\end{array}$ \\
\hline \begin{tabular}{|l|} 
Reflection \\
within \\
Learning \\
Increments
\end{tabular} & $\begin{array}{l}\text { Reflection in plenum } \\
\text { and development- } \\
\text { teams, based on } \\
\text { central questions }\end{array}$ & $\begin{array}{l}\text { At the end of each self- } \\
\text { learning phase within the } \\
\text { presence block }\end{array}$ & $\begin{array}{l}\text { Students and } \\
\text { teachers }\end{array}$ & $\begin{array}{l}\text { Learning progress of the } \\
\text { students (differences in the } \\
\text { teams); adaptions and } \\
\text { completions of the virtual } \\
\text { learning rooms; } \\
\text { understanding of the design } \\
\text { project to be performed }\end{array}$ \\
\hline $\begin{array}{l}\text { Final Project } \\
\text { Reflection }\end{array}$ & $\begin{array}{l}\text { Reflection in plenum } \\
\text { and team discussions } \\
\text { with teachers, based } \\
\text { on central questions }\end{array}$ & At the end of the project & $\begin{array}{l}\text { Students and } \\
\text { teachers }\end{array}$ & $\begin{array}{l}\text { Overall learning progress of } \\
\text { the students; outcome with } \\
\text { regard to engineering } \\
\text { methods (selection and } \\
\text { application), design } \\
\text { processes, team work and } \\
\text { social skills }\end{array}$ \\
\hline
\end{tabular}

\section{DISCUSSION}

The proposed concept of an agile learning-teaching process in engineering design courses is based on the concept proposed by Chun [6]. The adaption was performed based on the given frame conditions of the bachelor courses, with regard to the number of participants and duration of the design projects. During their initial implementations, the different elements of the concept were evaluated by surveys, focusing on the acceptance of the concept in general, the quality of the virtual learning rooms as well 
as the supportiveness of the different formats of reflection. Based on these evaluations, significant advantages of the concept are, as stated by students "it helps to keep in touch with the teachers more deeply based on our problems and questions" or "there is a great motivation resulting from the realworld problems and applications of engineering methods". However, so far there are no quantitative evaluations of the impact on the learning outcome of the students. Furthermore, as a part of future work, it has to be evaluated whether the concept is suitable to enable students to plan and evaluate their own development processes based on the modelling of design activities.

\section{CONCLUSION AND FURTHER RESEARCH}

Reflection skills are core competencies of engineering designers and are needed to navigate through complex and changing design tasks. Methods and processes from agile software engineering have established reflection as a core element in design processes. The proposed agile, project-based learning-teaching process described in this contribution is based on the character of agile design processes defining development increments (sprints) and reviews to ensure high quality of new developed functionalities. The agile learning-teaching comprises presence blocks for lectures, feedback and reflection, and virtual learning rooms, to support self-learning. In order to guide the individual learning processes of the students and provide additional learning contents by the teachers, different formats and dimensions of reflection are integrated into the learning-teaching process.

Future work will focus on the refinement of the concept of media-assisted agile learning-teaching processes regarding presentation and structure of the virtual learning rooms as well as the identification and evaluation of further methods for reflection. Another core area of research will be, to develop a concept which enables students to plan and evaluate development processes by themselves. Therefore, approaches form agile process engineering in project management [13] will be adapted to education.

\section{REFERENCES}

[1] Susskind R. and Susskind D. The Future of the Professions: How Technology Will Transform the Work of Human Experts, 2015 (Oxford University Press)

[2] Kamp A. Engineering Education in a Rapidly Changing World, Rethinking the Vision for Higher Engineering Education, 2016, 2nd Revised Edition, Delft, ISBN-978-94-6186-609-7

[3] Pries K.H. and Quigley J.M. Scrum Project Management, 2010 (CRC Press)

[4] N.N. Manifesto for Agile Software Development. Available: https://agilemanifesto.org/ [Accessed on 2019, 11 March], (2019) 11 March.

[5] Chromatic J.S. The Art of Agile Development: Pragmatic Guide to Agile Software DevelopmentTheory in practice, 2007, (O'Reilly Media, Inc.)

[6] Chun H.W. The Agile Teaching/Learning Methodology and its e-Learning Platform. In: Lecture Notes in Computer Science - Advances in Web-Based Learning, 3143, 2004, pp.11-18.

[7] Lauche K., Cardoso C.M., Badke-Schaub P. and Roozenburg N. Ways to Encourage Reflection on Design Methodology and Professional Practice. In: International Conference on Engineering and Product Design Education, E\&PDE 2008, Barcelona, September 2008, pp. 535-540

[8] Au K.H., Scheu J.A, Kawakami A.J., and Herman P.A. Assessment and accountability in a whole language curriculum. The Reading Teacher, 43, 1990, pp.574-578.

[9] Schön D.A. The Reflective Practitioner. How Professionals Think in Action. 1983, (Basic Books)

[10] Reiss N., Bavendiek A.-K., Diestmann G., Inkermann D., Albers A. and Vietor T. Understanding Design Methods - Using Explanatory Videos for Knowledge Transfer in Engineering Disciplines. In Procedia CIRP, 60, 2017, pp. 518-523.

[11] Kerres M. Mediendidaktik: Konzeption und Entwicklung digitaler Lernangebote. 2018, (De Gruyter)

[12] Bavendiek A.-K., Inkermann D. and Vietor T. Teaching design methods with the interactive 'Methodos' portal. In Proceedings of International Design Conference, DESIGN 2016, Mai 2016, Dubrovnik, pp. 2049-2058

[13] Baschin J., Inkermann D. and Vietor T. Agile Process Engineering to Support Collaborative Design. In Procedia CIRP Vol. 81, 2019 